\title{
LATERAL TELENCEPHALIC LESIONS AFFECT VISUAL DISCRIMINATIONS IN PIGEONS
}

\author{
JUAN D. DELIUS, RALF JÄGER and MARIA FRIESEL \\ Experimentelle Tierpsychologie, Psychologisches Institut, Ruhr-Universität, D 4630 Bochum. (F.R.G.)
}

Key words: lesions - lateral telencephalon - visual discrimination - pigeon

\begin{abstract}
The importance of the lateral telencephalon of the pigeon for visual performance was examined. Lesions in this area markedly impaired both the acquisition and the retention of instrumentally learned hue, intensity and pattern discriminations. Comparable lesions of the thalamofugal visual projection in the dorsoanterior telencephalon did not have an appreciable effect. Laterally lesioned pigeons showed only a minor, non-significant impairment in an instrumental auditory discrimination task. These results generally agree with findings of other authors on domestic chicks but disagree with previous work on pigeons. The visual discrimination performance of laterally lesioned subjects improved gradually over the course of days and weeks without specific experience being necessary, and after 3 months the recovery was virtually complete. The effect of lateral telencephalic lesions is discussed in connection with known visual projections within the avian endbrain and their relationship with other functional systems.
\end{abstract}

\section{INTRODUCTION}

While much progress concerning the function of the various structures of the avian telencephalon has been made in recent years, the role of some subdivisions remains uncertain. Salzen et al. ${ }^{30,31}$ reported that domestic chicks with ablations of the lateral forebrain while still showing approach to suitable objects in the context of filial imprinting, did not discriminate visually among them according to their imprinting experience. The ablations had this effect both proactively and retroactively. Further experiments ${ }^{32}$ suggested that, since innate object preferences were not affected, the lateral lesions were interfering with learning/memory processes and were not due to a perceptual impairment. Kohsaka et al. ${ }^{19}$ discovered that among other structures the lateral neostriatum of domestic chicks was activated during imprinting, as judged by an elevated $\mathrm{C} 14$ 2deoxyglucose uptake. Maier and Scheich ${ }^{21}$ presented similar findings relating to guinea fowl.
Horn ${ }^{13}$, on the other hand, reported that lateral telencephalic, unlike hyperstriatum ventrale lesions, did not affect the imprinting of chicks. Benowit $\mathrm{z}^{2}$ had earlier found that lateral forebrain lesions in chicks hindered the acquisition and retention of a visually mediated taste aversion conditioning. Benowitz and Lee Teng ${ }^{3}$ showed that lateral but somewhat more posteriorly placed lesions disturbed the early part of the acquisition of a thermally reinforced, orientation discrimination task in the same animals.

In contrast $Z$ eigler ${ }^{33}$ reported that lesions of the lateral forebrain in pigeons did not yield a deficit in operant pattern and brightness discrimination tasks. As part of a study on the visual role of the ectostriatum, Hodos and Karten ${ }^{12}$ made less extensive ablations, portions of the lateral telencephalon of pigeons and also found no impairment in instrumental brightness, orientation and pattern discrimination learning. However McCollum and Goodman ${ }^{20}$ found that electrical stimulation of the lateral telencephalon of pigeons had an 
amnesic effect on the retention of a passive avoidance task but that did not involve any intentional visual cues.

Ritchie $^{28}$ (see also ref. 29) anatomically described secondary visual projections originating in the Wulst and ectostriatum, both well known primary telencephalic visual areas ${ }^{11}$, as reaching the dorsal archistriatum and the caudolateral portions of the neostriatum (compare also ref. 18). Less definite evidence to the same effect can also be found elsewhere ${ }^{1,14,25,27}$. It also seems that the posterolateral neostriatum and/or the mediodorsal archistriatum also receives a direct projection from a brainstem visual centre ${ }^{10,22}$.

An unpublished preliminary experiment of ours indicated that lateral lesions in pigeons yielded a profound visual discrimination deficit that contrasted with the minor defect produced by comparable lesions of the Wulst, a main visual projection area of the telencephalon. We now report formal experiments confirming and extending these findings.

\section{METHODS}

Adult homing pigeons (Columba livia) of local stock were used. They were kept in cages with a lighting regime of $12 \mathrm{~h}$ on, $12 \mathrm{~h}$ off. They were food deprived to $80 \%$ of their normal weight and remained at that level throughout. All the subjects were pretrained to peck the two response keys of a conventional skinner-box for food reward.

Surgery was performed while the animals were under barbiturate/chloral-hydrate anaesthesia and their heads were held in a stereotaxic hold$\mathrm{er}^{15}$. The skull was exposed and trephined over the target area with a dental burr. The lateral aspects of the telencephalon were removed by aspiration after it had been separated from the remaining brain with longitudinal scalpel cuts. The hyperstriatal tissue (only Expt. I) was simply removed by aspiration after the dura had been slit. The wounds were loosely filled with surgical gelatine foam. Sham operations involved burring the skull-bone but without reaching the dura. The postoperative behaviour of the subjects was closely observed, but apart from a slight hypophagia lasting 1 or 2 days that affected a few laterally lesioned birds, nothing particular was noticed.

After the behavioural testing was completed, the animals were perfused with saline and formalin. The brains were removed and cut in the frontal plane with a freezing microtome at $40 \mu \mathrm{m}$. Sections at approximately $0.5 \mathrm{~mm}$ intervals were mounted and stained with cresyl-violet. The sections were examined under the microscope and the extent of the lesions transferred onto drawings taken from Karten and Hodos ${ }^{15}$ pigeon brain atlas.

For Expts. I, II and III, the subjects were trained concurrently on a hue, an intensity and a shape discrimination with a simultaneous, discrete trial procedure. Each task was learned in separate sessions that alternated according to a randomized design across the subjects and groups. The stimuli were back-projected on the two keys of a conventional Skinner-box with the aid of multichannel microprojectors. The hue discrimination involved yellow (Wratten no. 9) and orange (Wratten no. 16) lights approximately matched for equal pigeon subjective brightness with neutral density filters according to Blough's ${ }^{4}$ spectral sensitivity comparison between man and pigeon. Additionally, one or the other colour was randomly dimmed by $0.2 \log$ units, making remaining intensity differences irrelevant. The intensity discrimination involved bluish (Wratten no. $80 \mathrm{~A}$ ) light, either unattenuated, or attenuated with a $0.3 \log$ unit neutral density filter. The shape discrimination involved a white square and a white circle of the same surface area $\left(56 \mathrm{~mm}^{2}\right)$ on a dark background. From preliminary experiments it was known that the 3 tasks were of similar difficulty for pigeons.

All events within a session were controlled by modular logic programming equipment. A trial began with the relevant stimulus pair being backprojected on the keys. When the animal pecked the key bearing the positive stimulus, the stimuli extinguished, food was offered for $3 \mathrm{~s}$ and the next trial began immediately afterwards, the left-right positions of the stimuli being determined by a quasi-random sequence ${ }^{9}$. If the subjects responded to the negative stimulus, the stimuli and a houselight extinguished for $16 \mathrm{~s}$ before the next 
trial began in which the stimulus positions were retained, thus instituting a correction procedure. A timer-printer registered the response latencies and counters recorded the correct and incorrect responses. Daily sessions, weekends excepted, consisting of 32 non-correction trials were given.

The design of Expts. I and II had in common that half of the subjects in each learned the tasks described above before surgery and were retrained on them afterwards (retention group) whereas the other half of the subjects only learned the discriminations after the operation (acquisition group). The preoperative learning of the retention group terminated when each animal yielded two successive sessions with $29(90.6 \%)$ correct trials in each of the 3 tasks. Retention was tested in 30 postoperative sessions, 10 of each assessed task with the same procedures described above.

Twenty-four pigeons participated in Expt. I. One third of them received lateral lesions, another third hyperstriatal lesions and the remainder was sham operated. Sixteen pigeons took part in Expt. II, one half receiving lateral lesions, the other half being sham operated. While retention assessment and acquisition training in Expt. I was begun 4-5 days after surgery, in Expt. II it began 15 weeks after that event. During this extended period the animals were kept in an outside aviary.

Sixteen pigeons were used in Expt. III. There was only a retention group, half of them were sham operated, a quarter of the animals receiving anteriorly placed lateral lesions, the remaining quarter having posteriorly placed lateral lesions. Otherwise the procedures were equivalent to those of Expt. I.

Eight pigeons served as subjects in Expt. IV. They were trained to discriminate between a $40 \mathrm{~ms}$ and a $10 \mathrm{~ms}$ transient-free tone burst of $2500 \mathrm{~Hz}$ at $100 \mathrm{~dB}\left(\right.$ re $0.002 \mathrm{dyne} / \mathrm{cm}^{2}$ ). A procedure that overcomes the notorious reluctance of pigeons to learn fine auditory discriminations in appetitive, operant conditioning situations was used $^{7,16}$. The same apparatus described earlier was used after some modifications. A trial began with both multiply perforated keys being illuminated with dim diffuse white light. The subjects pecked one of the two keys. The peck elicited a stimulus tone from a loudspeaker placed immediately behind the corresponding key. If the stimulus issuing from the key was that defined as correct and the animal continued to peck the particular key 16 times, on each occasion triggering the positive tone as feedback, then the key lights extinguished and food was offered. The next trial began with the two tone stimuli being allotted to the two keys according to a quasi-random schedule ${ }^{9}$. Pecks to the incorrect key each time triggered the negative tone and nothing ever happened. Only when the animal shifted its pecking to the correct key and tone, it received reinforcement after 16 consecutive responses and a new trial began. The number of trials per session was 32 . After the animals had reached a criterion of 3 consecutive sessions with above $80 \%$ correct responses they were assigned to two groups. One of them received lateral forebrain lesions, the other was sham-operated. After recovery of 4 or 5 days they were retrained for 10 further sessions. The results of the various experiments were statistically examined with analyses of variance for repeated measurement designs according to ref. 17.

\section{RESULTS}

The number of correct responses per session by each subject was converted into percentages. Means of these percentages were calculated separately for the different tasks and the various groups of ablated and control subjects.

Fig. 1 shows the resulting mean learning curves for the various groups and tasks of Expt. I. The lateral forebrain lesions affected both the acquisition and the retention of most discriminations, (each $F 1 / 6 \geqslant 21.03, P<0.01$; except brightness acquisition $F 1 / 6=6.09, P<0.05$; but colour and brightness retention $F 1 / 6 \leqslant 4.64, P>0.05$ ), the Wulst lesions, on the other hand, did not produce more than slight deficits all $(F 1 / 6 \leqslant 5.56, \quad P>0.05$ except brightness retention $F 1 / 6=35.68, P<0.01$ and pattern retention $F 1 / 6=7.59, P<0.05$ ). This latter result confirms much earlier evidence that this area, although containing a well established visual projection is not essential for the kind of performance 

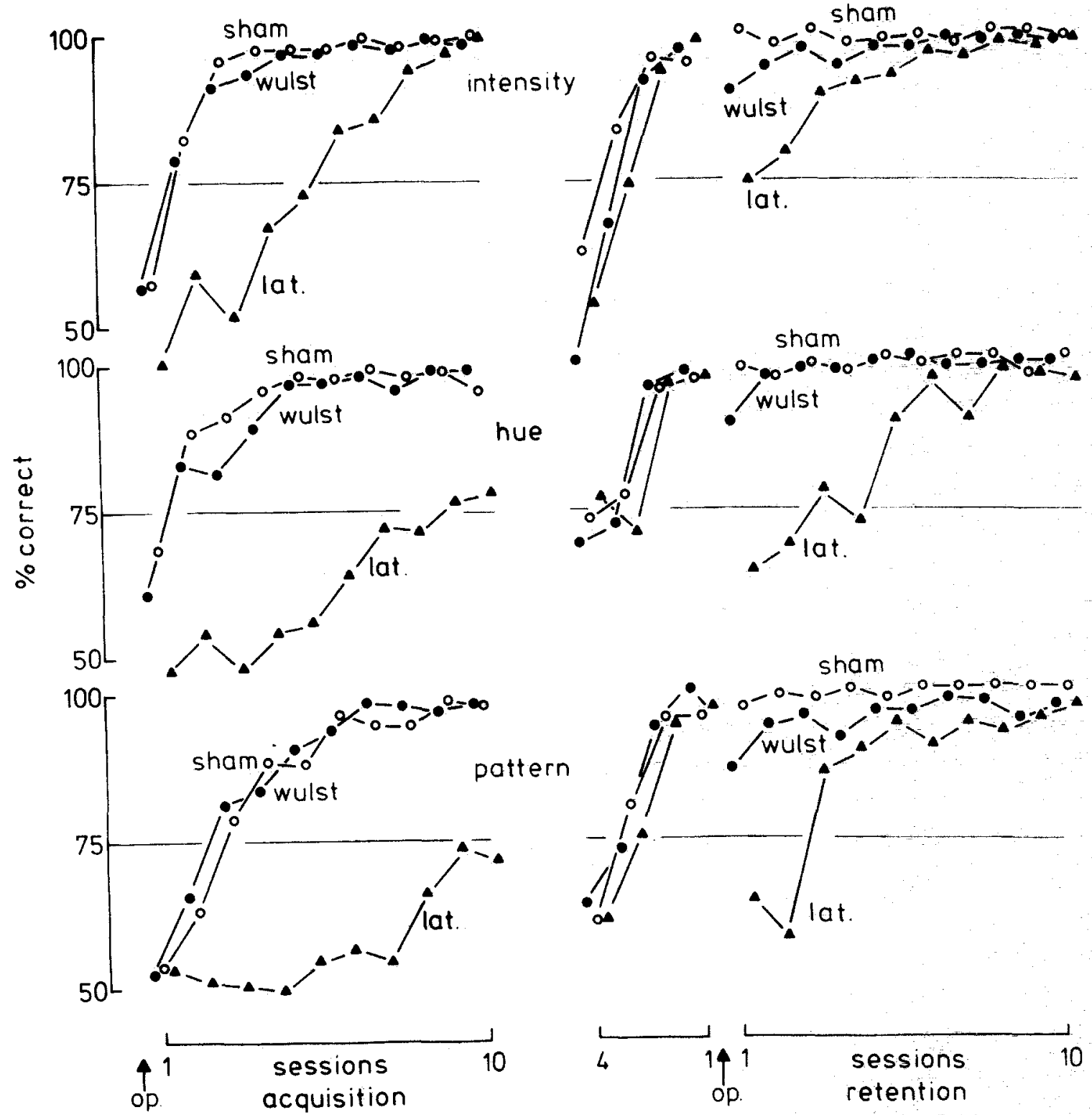

Fig. 1. Mean performance in 3 visual discrimination tasks by pigeons with sham lesions, Wulst lesions and lateral forebrain lesions (Expt. I). Left: pre-acquisition lesioned pigeons. Right: post-acquisition lesioned pigeons.

tested here (but see ref. 23). Table I presents the mean response latencies during the postoperative phase. There is a tendency for the latencies of the laterally lesioned animals to be longer but the differences are not significant (all $F 2 / 10<5.99$. $P>0.05$ ).

The extent of the lesions is shown in Fig. 2. They varied somewhat in extent and position but all affected the most lateral $2 \mathrm{~mm}$ of the endbrain tissue from about frontal planes A6 to A12. The ablations involved the anterolateral hyperstriatum ventrale, the lateral neostriatum, the area temporo-parieto-occipitalis, the anteroventral portion of the area corticoidea dorsolateralis and the dorsal part of the cortex piriformis ${ }^{15}$. In a few subjects the lesions also encroached upon the outermost edge of the ectostriatum and the anterior archistriatum and in some cases the tractus archistriatalis dorsalis. It was not possible to relate the degree of behavioural deficit of individuals 
TABLE I

Mean response latencies in $s$ during the postoperative acquisition and retention of visual discriminations by pigeons

\begin{tabular}{llll}
\hline Discrimination & \multicolumn{1}{c}{ Lesion } & & \\
\cline { 2 - 4 } & Sham & Wulst & Lateral \\
\hline $\begin{array}{l}\text { Intensity } \\
\text { Acquisition }\end{array}$ & 1.18 & 1.49 & 1.83 \\
Retention & 1.31 & 1.30 & 1.33 \\
Hue & & & \\
Acquisition & 1.17 & 1.40 & 1.60 \\
Retention & 1.27 & 1.23 & 1.53 \\
& & & \\
Pattern & & & 1.65 \\
Acquisition & 1.16 & 1.23 & 1.55 \\
Retention & 1.12 & 1.20 & \\
\hline
\end{tabular}

to the particular lesions they bore, in particular subjects with ectostriatal damage were definitely no worse than the others. The Wulst lesions, though more variable in outline, had an extent comparable to the lateral lesions (Fig. 2). Since they served only as control lesions and yielded few performance deficits they will not be further described except stating that the visual projection area in this region ${ }^{11}$ was mostly totally destroyed.

In Expt. II with the long postoperative recovery period only slight initial performance differences between the lesioned and non-lesioned animals were observed. Analyses of variance results showed these not to be significant $(F 1 / 6 \leqslant 5.16$. $P>0.05) \quad$ except brightness retention $F 1 / 6=9.63, P<0.05$ ). A small initial deficit however was observed in all 6 component tests of the experiment. For space saving reasons Fig. 3 only shows average curves over the 3 discrimination tasks. The performance of the animals tested for postoperative acquisition can be directly compared with that of the corresponding group of Expt. I since the sham operated controls yielded very similar learning curves. The laterally lesioned animals of Expt. II did significantly better than those of Expt. I $(F 1 / 6=12.77$, $P<0.05)$. An analogous comparison of the retention groups is not possible because of the greater forgetting shown by the Expt. II controls due no doubt to the longer interval before retention testing. As the lesions of these birds were closely similar to the lateral ablations shown in Fig. 2 they are not illustrated. They were, however, more difficult to delineate. It would seem that appreciable tissue reorganization/regeneration had taken place but the histological material available does not allow a definite judgement on this point.

Both the anterior and posterior lateral lesions of Expt. III affected the discrimination performance but the deficit of the anterior group seems somewhat more marked according to the average curves shown in Fig. 3. However in this latter group only the brightness task yielded a significant difference between control and lesioned subjects $(F 1 / 6=9.63, P<0.05)$ whereas significant differences were apparent in all 3 tasks in the case of the posteriorly lesioned animals (intensity and pattern $F 1 / 6 \geqslant 17.46, P<0.01$, hue $F 1 / 6=8.52, P<0.05)$. This disparity may be explained by the more heterogenous lesion placement in anterior group.

The extent and location of the lesions is shown in Fig. 4. The anterior lesions extended mostly from frontal plane A9 to A13 involving the lateral neostriatum and the most lateral portions of the hyperstriatum ventrale. In two cases the ectostriatum was also slightly affected. Three birds that showed marked discrimination deficits had relatively posteriorly located lesions, one that only revealed a slight impairment had rather anteriorly placed lesions (A11 to A14). The posterior lesions were somewhat more extensive and stretched from A4 to A10 involving the lateral neostriatum, the area temporo-parieto-occipitalis, the lateral portions of the area corticoidea dorsolateralis, the outermost portions of the archistriatum including the cortex piriformis and in some cases the ventral portions of the tractus archistriatalis dorsalis.

The mean discrimination learning curves of the auditory task (Expt. IV) are shown in Fig. 3. It is important to note that due to the type of task employed the best performance attainable is less than $100 \%$ correct because the subjects can only identify the correct key after the minimum of one, potentially incorrect, peck per trial. The postoper- 

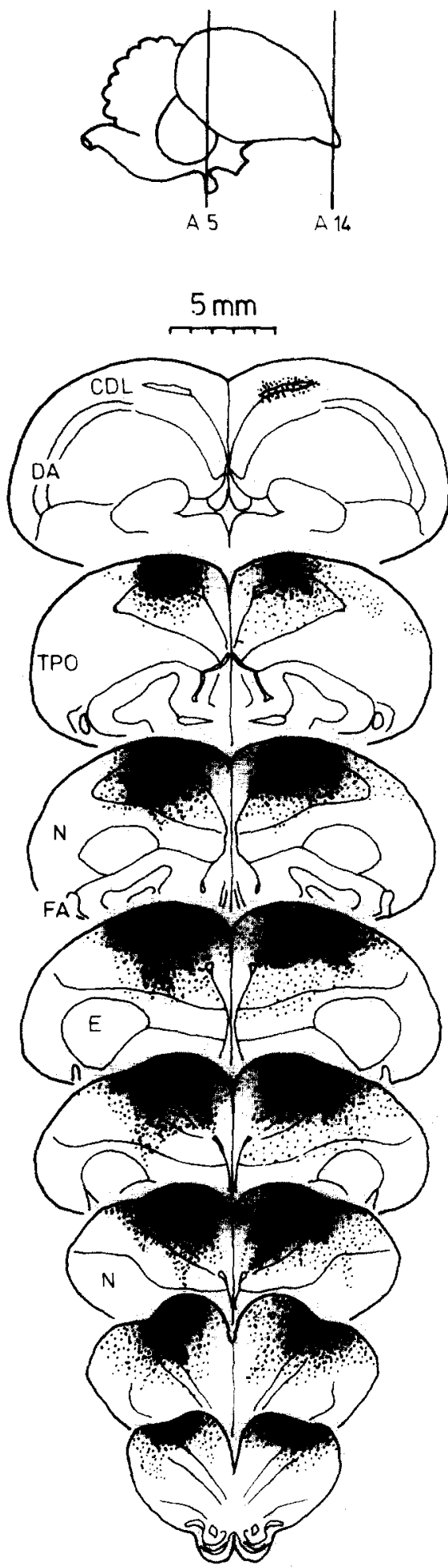

A 5

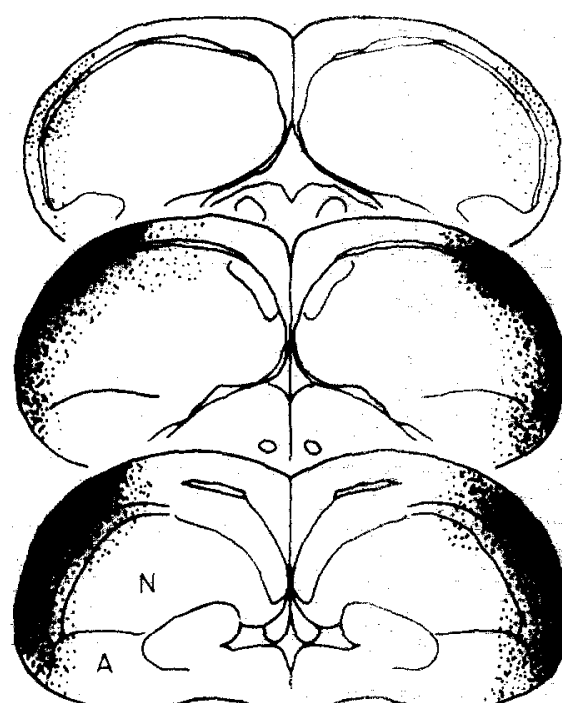

A 8

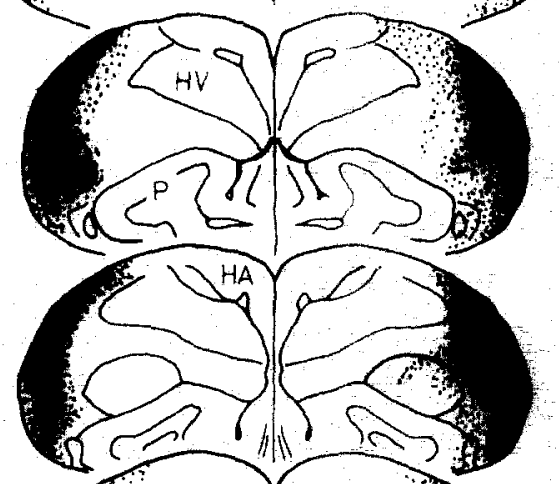

A 9

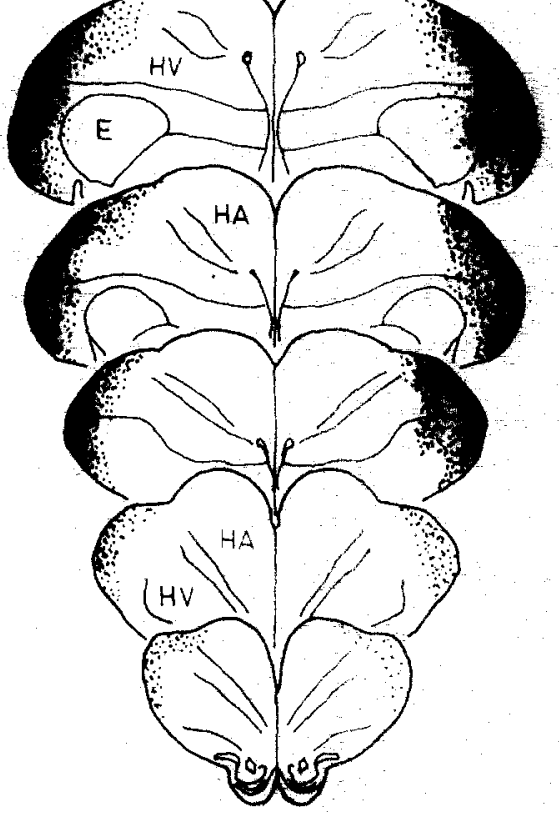

Fig. 2. Lateral forebrain (right) and Wulst (left) lesions of the Expt. I pigeons. Schematic brain section drawings are derived from ref. 15. The heaviness of stippling indicates the degree of overlap of the lesions in the individual animals. Abbreviations: A, archistriatum; CDL, area corticoidea dorsolateralis; DA, tractus archistriatalis dorsalis; $\mathrm{E}$, ectostriatum; $\mathrm{FA}$, tractus frontoarchistriatalis; HA, hyperstriatum accessorium; HV, hyperstriatum ventrale; N, neostriatum; $\mathrm{P}$, paleestriatum; TPO, area temporo-parieto-occipitalis. 

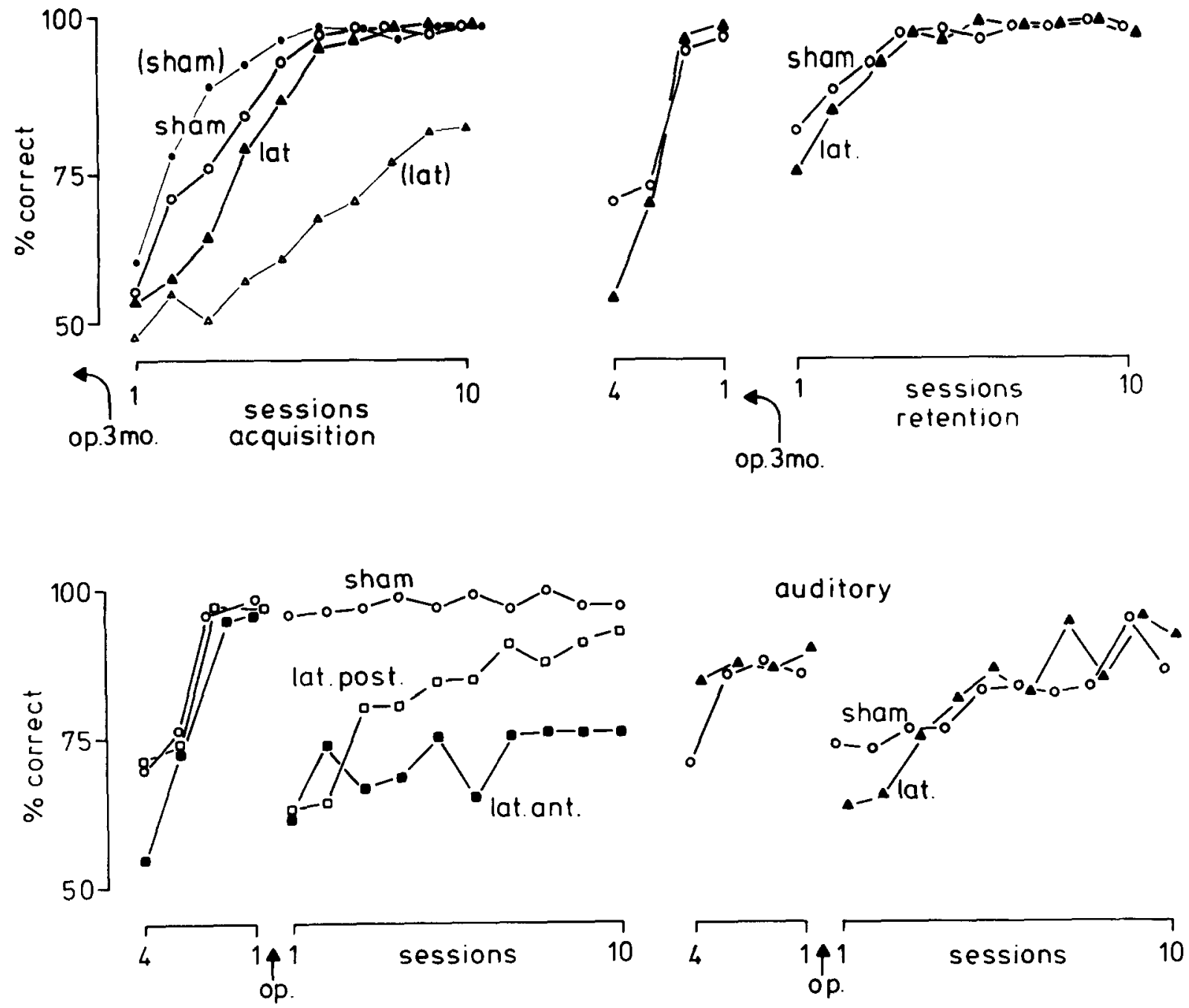

Fig. 3. Top: average discrimination performance of sham lesioned and lateral forebrain lesioned pigeons (Expt. II). There was a 3-month post-operation recovery before performance testing began. Left: pre-acquisition lesioned pigeons. The average performance of the corresponding groups of Expt. I have been included for comparison (thin lines, brackets). Right: post-acquisition lesioned pigeons. Bottom left: average discrimination learning curves of anterior and posterior lateral forebrain lesioned and sham operated pigeons (Expt. III). Bottom right: mean auditory discrimination performance of sham operated and lateral forebrain lesioned pigeons (Expt. IV).

ative performance of both the lateral-lesioned and the sham-lesioned animals dropped. The difference between the groups however is slight and transitory. An analysis of variance furthermore reveals that it is non-significant $(F 1 / 6=0.04$, $P>0.05)$. The lateral telencephalic ablations of the animals participating in this experiment were closely similar to those illustrated in Fig. 2 except in one case where their location was somewhat more anterior, extending from frontal plane A7 to A13.

\section{DISCUSSION}

Since lesions of the lateral forebrain impair visual discrimination performance both during the acquisition phase and during postoperative retention testing it has a visual function in the pigeon. These results agree in a general way with the findings of Salzen and collaborators ${ }^{30-32}$ in the chick, but do not support the suggestion that lateral brain lesions might specifically affect hue discrimination in an imprinting context as instru- 


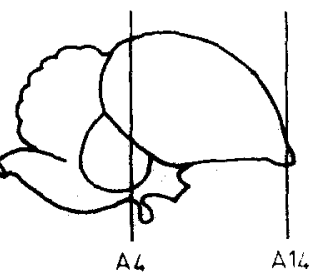

A 4

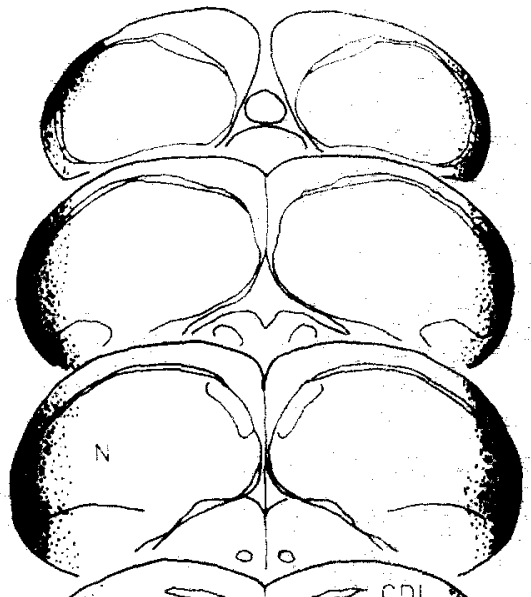

A 6

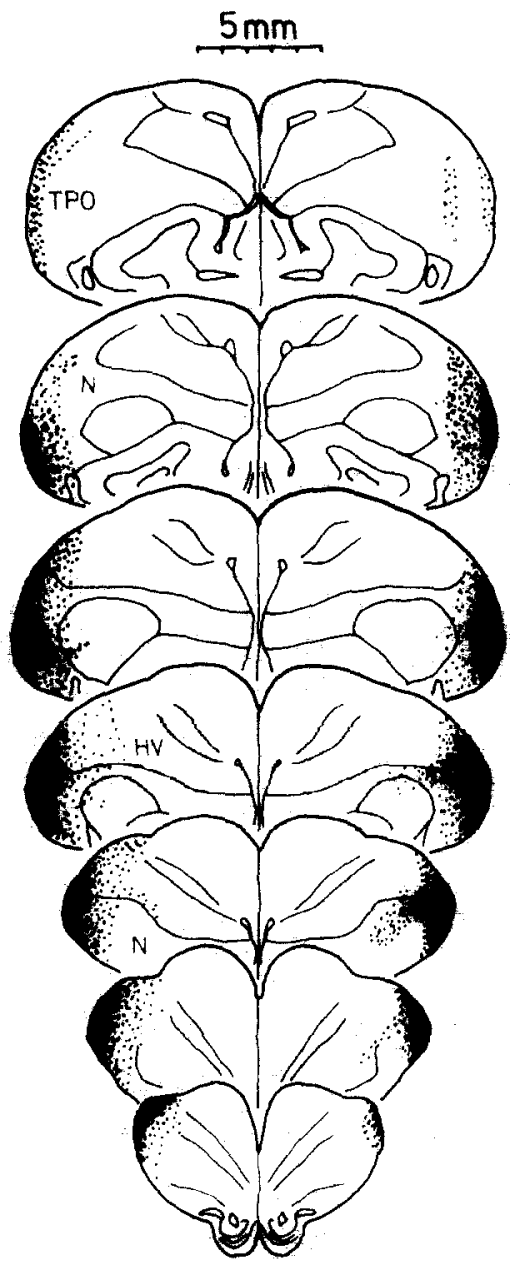

A 7

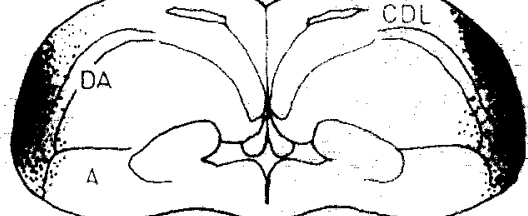

A 8

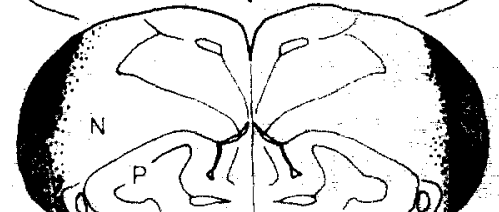

A 9

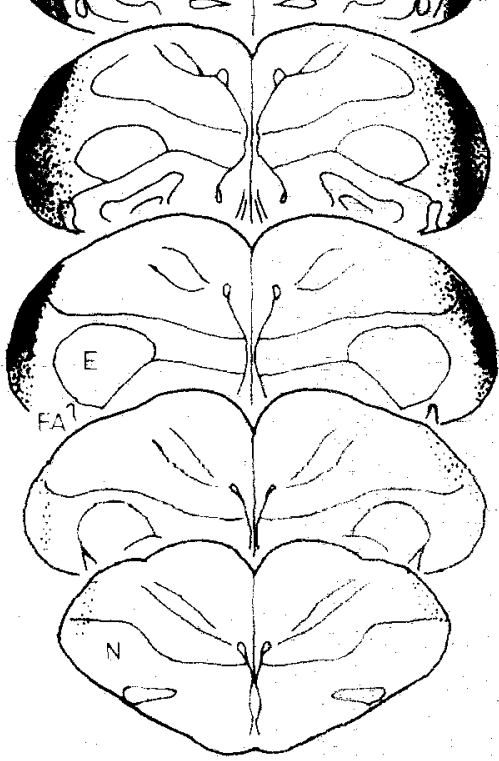

A 13

A 14

Fig. 4. Anterior (left) and posterior (right) lateral forebrain lesions of the pigeons of Experiment IV. The stippling density reflects the degree of overlap among the lesions of the different individuals. Abbreviations as in Fig. 2. 
mentally conditioned intensity and brightness and pattern discriminations were affected in the pigeon. The deficit may be specific to vision as the auditory discrimination of Expt. IV was not significantly affected by lateral lesions. However it would seem wise to defer a final decision on this point until further data has accrued. This, and also the fact that the response latencies of the laterally lesioned and the control animals during the visual tasks did not differ significantly, suggests that the deficit was not of a simple motoric or motivational nature. As to whether the defect is due to an impairment of visual perception or visual memory we are inclined to believe that the former is the case. This is based on the fact that both acquisition and retention performance were similarly affected by the lesions and that furthermore in the case of the delayed retention tests of Expt. II, the laterally lesioned pigeons had not forgotten the discriminations, any more than the sham operated controls had.

Expt. I demonstrated a recovery of function with the progression of retraining sessions. The results of Expt. II indicate that there is an almost complete recovery of function after 3 postoperative months in the absence of specific task experience. The histology suggests that this may be associated with an extensive neuronal reorganization and regeneration. That is the subject of current research.

The lateral forebrain is known to receive primary telencephalic secondary afferences from known visual projection and the Wulst and the ectostriatum $^{18.28}$. Those from the Wulst cannot be crucial for the functions we disturbed with the lateral lesions since the Wulst ablations themselves had minor effects on the performance of the same tasks. The afferences from the ectostriatal complex might be relevant although the performance of individual birds which had lesions encroaching on this structure was not worse than that of those that did not. Secondary afferences from the caudally situated archistriatal/neostriatal primary and secondary visual projection described by Güntürkün ${ }^{10}$ are a further possibility, even though Parker ${ }^{24}$ extensively lesioned the caudal telencephalon of pigeons finding little impairment of visual function.
The present results also have indirect import on the role of the ectostriatum. While one study reported no deficit of visually controlled classical heart-rate conditioning after ectostriatal coagulations ${ }^{5}$, another study that examined the effect of its ablation on instrumental visual discriminations reported drastic deficits ${ }^{12}$. In the latter study the lateral telencephalon was however also extensively damaged. Control lesions of this area alone did not yield any deficit. Why these ablations and other similar ones of an earlier experiment ${ }^{33}$ with pigeons did not lead to visual deficits is a matter of conjecture in view of the many differences in procedure and the somewhat different geometry of the lesions. It is also possible that prolonged postoperative recovery periods were allowed. A re-examination of the ectostriatum's role using a more neutral access would however seem necessary in the light of the present results.

The possibility that more anterior lateral lesions may have a more marked effect than more posterior ones suggests that the defects could be due to the impairment of visual inputs to the sensory-motor system that is centred around the nucleus basalis and involves also the tractus quintofrontalis, the tractus frontoarchistriatalis and the archistriatum anterior. This system is thought to be implicated in the control of pecking ${ }^{8,18,34}$ a response that is well known to be under a close but highly plastic visual control in pigeons ${ }^{6}$.

\section{ACKNOWLEDGEMENTS}

The work was supported by the Deutsche Forschungsgemeinschaft through its Sonderforshungsbereich 114. The special cooperation of D. Thünken, J. Okrongli, G. Bejar, G. Sommer and U. Schall is gratefully acknowledged. We also thank H. Stankewitz, A. Lohmann, O. Güntürkün, J. Emmerton and D. Hagenkötter for assistance on various matters.

\section{REFERENCES}

1 Belekhova, M.G., Subcortico-cortical relationships in birds, Neurosci. Transl., 2 (1968) 195-203.

2 Benowitz, L., Effects of forebrain ablations on avoidance learning in chicks, Physiol. Behav., 9 (1972) 601-608. 
3 Benowitz, L. and Lee Teng, E., Contrasting effects of three forebrain ablations on discrimination learning and reversal in chicks, J. comp. physiol. Psychol., 84 (1973) 391-397.

4 Blough, D.S., Spectral sensitivity in the pigeon, J. opt. Soc. Amer., 47 (1957) 827-833.

5 Cohen, D.H. and Trauner, D.A., Studies of avian visual pathways involved in cardiac conditioning: nucleus rotundus and ectostriatum, Exp. Brain Res., 7 (1969) 133-142.

6 Delius, J.D., Learning. In M. Abs (Ed.), Physiology and Behaviour of the Pigeon, Academic, London, 1983

7 Delius, J.D. and Emmerton, J., Stimulus-dependent asymmetry in classical and instrumental discrimination learning by pigeons, Psychol. Rec., 28 (1978) 425-434.

8 Delius, J.D., Runge, T.E. and Oeckinghaus, H., Short-latency auditory projection to the frontal telencephalon of the pigeon, Exp. Neurol., 63 (1979) 594-609.

9 Fellows, B.J., Chance stimulus sequences for discrimination tasks, Psych. Bull., 67 (1976) 87-92.

10 Güntürkün, O., A third primary visual area in the telencephalon of the pigeon, Brain Res., in press.

11 Hodos, W., Vision and the visual system: a bird's-eye view, Progr. Physiol. Psychol., 6 (1976) 29-62.

12 Hodos, W. and Karten, H.J., Visual intensity and pattern discrimination deficits after lesions of ectostriatum in pigeons, J. comp. Neurol, 140 (1970) 53-68.

13 Horn, G., Neural mechanisms of learning: an analysis of imprinting in the domestic chick, Proc. roy. Soc. B, 213 (1981) 101-137.

14 Karten, H.J., The organization of the avian telencephalon and some speculations on the phylogeny of the amniote telencephalon, Ann. N.Y. Acad. Sci., 167 (1969) 164-179.

15 Karten, H.J. and Hodos, W., A Stereotaxic Atlas of the Brain of the Pigeon (Columba livia), Johns Hopkins, Baltimore, MD, 1967.

16 Kinchla, J., Discrimination of two auditory durations by pigeons, Percept. Psychophys., 8 (1970) 299-307.

17 Kirk, R., Experimental Design: Procedures for the Behavioural Sciences, Brooks/Cole, Belmont, CA, 1968

18 Kitt, C.A. and Brauth, S.E., Neural connections of the avian lateral corticoid areas, Soc. Neurosci. Abstr., (1978) 45

19 Kohsaka, S., Takamatsu, K., Aoki, E. and Tsukada, Y., Metabolic mapping of chick brain after imprinting using C14 2-deoxyglucose technique, Brain Res., 172 (1979) 539-544.

$20 \mathrm{McCollum}, \mathrm{R} . \mathrm{H}$. and Goodman, I.J., Brain perturbation and memory disruption: a comparison between classes. In I.J. Goodman and M.W. Schein (Eds.), Birds, Brain and Behavior, Academic, New York, 1974, pp. 203-220.
21 Maier, V. and Scheich, H., Acoustic imprinting leads to differential 2-deoxy-D-glucose uptake in the chick forebrain, Proc. nat. Acad. Sci. U.S.A. 80)(1983) 3860-3864.

22 Minelli. G., Faccioli, G. and De Liberali, M., Experimental study on the nervous connections of some diencephalic and mesencephalic nuclei in Cotumix coturnix japonica, J. Hirnforsch., 20 (1979) 217-232

$23 \mathrm{Nau}, \mathrm{F}$. and Delius, J.D., Discrepant effects of unilateral and bilateral forebrain lesions on the visual performance of pigeons, Behav. Brain Res., 2 (1981) 119-124.

24 Parker, D.M. Electrophysiologicat and Behavioral Studies of Vision in the Pigeon, Ph.D. Thesis, 1971, University of Durham, U.K.

25 Parker, D.M. and Delius, J.D., Visual evoked potentials in the forebrain of the pigeon, Exp. Brain Res., 14 (1972) 198-209.

26 Parker, D.M. and Delius, J.D. The effects of wulst lesions on simple visual discrimination performance in the pigeon, Behav. Proc., 5 (1980) 151-159

27 Phillips, R.E., Evoked potential study of connections of avian archistriatum and caudal neostriatum, $J$ comp. Neurol., 127 (1966) 89-99.

28 Ritchie, T.L.C., Intratelencephalic Visual Connections and their Relationship to the Archistriatum in the Pigeon (Columba livia), Ph.D. Diss., Univ. of Virginia, Charlottesville, VI, 1979.

29 Ritchie, T.L.C. and Cohen, D.H, The avian tectofugal visual pathway: projections of its telencephalic target, the ectostriatal complex, Soc. Neurosci. Abstr., 3 (1977) 275.

30 Salzen. E.A., Parker, D.M. and Williamson, A.J., A forebrain lesion preventing imprinting in domestic chicks, Exp. Brain Res., 24 (1975) 145-157

31 Szalzen. E.A., Parker, D.M and Williamson, A.J., Forebrain lesions and retention of imprinting in domestic chicks. Exp. Brain Res., 31 (1978) 107-116.

32 Salzen, E.A., Williamson, A.J. and Parker, B.M., The effects of forebrain lesions on innate and imprinted colour, brightness and shape preferences in domestic chicks, Behav. Proc., 4 (1979) 295-313.

33 Zeigler, H.P., Effects of endbrain lesions upon visual discrimination learning in pigeons, $J$. comp. Neurol, 120 (1963) 161-181.

34 Zeigler. H.P., Feeding behavior in the pigeon: a neurobehavioral analysis. In I.J. Goodman and M.W. Schein (Eds.), Birds, Brain and Behavior, Acadamic, New York, 1974, pp. 101-132. 